\title{
Clinical Inertia in Poorly Controlled Elderly Hypertensive Patients: A Cross-Sectional Study in Spanish Physicians to Ascertain Reasons for Not Intensifying Treatment
}

\author{
Vicente Gil-Guillén · Domingo Orozco-Beltrán · Concepción Carratalá-Munuera • \\ Emilio Márquez-Contreras • Ramón Durazo-Arvizu • Richard Cooper • \\ Salvador Pertusa-Martínez • Salvador Pita-Fernandez • Diego González-Segura • \\ José Luis Martin-de-Pablo • Vicente Pallarés · Antonio Fernández • \\ Josep Redón
}

Published online: 13 April 2013

(C) Springer International Publishing Switzerland 2013

\begin{abstract}
Background Clinical inertia, the failure of physicians to initiate or intensify therapy when indicated, is a major problem in the management of hypertension and may be more prevalent in elderly patients. Overcoming clinical inertia requires understanding its causes and evaluating certain factors, particularly those related to physicians.

Objective The objective of our study was to determine the rate of clinical inertia and the physician-reported reasons for it.

Methods An observational, cross-sectional, multi-center study was carried out in a primary care setting. We

V. Gil-Guillén $(\bowtie) \cdot$ D. Orozco-Beltrán .

C. Carratalá-Munuera $\cdot$ S. Pertusa-Martínez

D. González-Segura · V. Pallarés · A. Fernández

Cátedra de Medicina de Familia, Departamento de Medicina

Clínica, Universidad Miguel Hernández, Ctra. De Valencia

N332 Km 87, San Juan, 03550 Alicante, Spain

e-mail: atencion.primaria@umh.es; dorozcobeltran@gmail.com

V. Gil-Guillén

Research Unit, Elda Hospital, Alicante, Spain

D. Orozco-Beltrán

Research Unit, San Juan Hospital, Alicante, Spain

E. Márquez-Contreras · J. L. Martin-de-Pablo

Treatment compliance and inertia research group, Spanish

Society of Hypertension, Alicante, Spain

R. Durazo-Arvizu - R. Cooper

Loyola University, Chicago, IL, USA

S. Pita-Fernandez

A Coruña University, A Coruña, Spain

J. Redón

Valencia University, Clínico Universitario Hospital, Valencia, Spain
\end{abstract}

included 512 physicians, with a consecutive sampling of 1,499 hypertensive patients with clinical inertia.

Main Outcome Measure Clinical inertia was defined when physicians did not modify treatment despite knowing that the therapeutic target had not been reached. Clinical inertia was considered to be justified (JCI) when physicians provided an explanation for not intensifying treatment and as not justified (nJCI) when no reasons were given.

Results JCI was observed in $30.1 \%$ (95\% CI 27.8-32.4) of patients $(n=451)$ and nJCI in $69.9 \%(95 \%$ CI 67.6-72.2) $(n=1,058)$. JCI was associated with higher blood pressure (BP) values (both systolic and diastolic) and diabetes $(p=0.012)$ than nJCI. nJCI was associated with patients having an isolated increase of systolic or diastolic or high borderline BP values or cardiovascular disease.

Conclusion Physicians provided reasons for not intensifying treatment in poorly controlled patients in only $30 \%$ of instances. Main reasons for not intensifying treatment were borderline BP values, co-morbidity, suspected white coat effect, or perceived difficulty achieving target. nJCI was associated with high borderline BP values and cardiovascular disease.

\section{Introduction}

More than one-third of patients receiving treatment for hypertension in the US have uncontrolled blood pressure (BP) [1]. BP control rates for hypertension fall far short of the expected goals, especially in older hypertensive patients with high systolic BP (SBP) or isolated systolic hypertension [1-3]. In 2001, Phillips et al. [4] defined clinical inertia as failure by physicians to initiate or intensify clinical therapy when indicated, and the Joint National Committee (JNC)VII report accepted clinical inertia as an important reason for 
the lack of adequate BP control in hypertensive patients [5]. Overcoming clinical inertia requires an understanding of its causes [6] and evaluating the associated variables, particularly those related to physician attitudes $(50 \%)$, patientrelated characteristics (30\%), and the level of healthcare (20\%) [4, 7-9]. A study from our group conducted in hypertensive patients aged $>40$ years found that clinical inertia was present in one of every three cases of high BP [10]. Amongst the variables associated with clinical inertia, co-morbidity, which requires lower BP goals, was the most important [10]. Several studies [11-14] have shown that clinicians do not consider small elevations above goal BP to be a cause for concern. But reasons for not intensifying treatment have not been widely explored in ageing patients. Therefore, we designed a new study to explore clinical inertia in aged patients in Spain. Previously, we have reported [15] the magnitude of clinical inertia to be $42.1 \%$ in poorly controlled, aged hypertensive patients with several associated factors (older age, lack of co-morbidity, and being seen at a primary care center). In this study, we analyze physicians' self-reported rationale for clinical inertia.

\section{Material and Methods}

We undertook an observational, cross-sectional, multicenter study involving ambulatory patients from primary care centers and hospital hypertension units in Spain. We followed the BP recommendations from the seventh report of the JNC [5] and the European Task Force for the Management of Arterial Hypertension [16]. Our participant physicians adopted a conservative attitude of not modifying treatment despite knowing that the therapeutic target had not been reached [4]. Clinical inertia was classified as 'justified' when a reason was given and 'not justified' when physicians marked the option 'no reasons to give'. A total of 512 physicians participated in the study between February and June 2007. Information about the problem of clinical inertia and the guideline-recommended goals [4, 5, 8] was sent to physicians, who were selected in a random manner from a primary care physicians group from the Spanish Society of Arterial Hypertension. They come from different regions in Spain. Of the physicians who were invited to participate, $8 \%$ declined.

Physicians were informed about other causes of poor BP control, such as white coat hypertension, therapeutic noncompliance, incorrect BP measurement, or interactions with other drugs in order to assist them in assigning a reason for not changing treatment.

Using consecutive sampling, each physician included 8-12 poorly controlled hypertensive patients who came for a routine visit. The inclusion criteria were as follows: hypertensive patients diagnosed according to the 2003 criteria of the European Societies of Hypertension and Cardiology, [17] providing signed informed consent, either sex, aged $\geq 50$ years, having arterial hypertension diagnosed at least 6 months previously, and receiving stable drug treatment for at least 4 weeks. Patients were excluded if they had any severe mental or social problem or if they were hypertensive patients with a very low life expectancy.

This report is the continuation of a wider study about clinical inertia. The first paper [15] analyzed the magnitude of clinical inertia and its associated factors. The sample size was calculated to be 4,860 hypertensive patients [15]. For this study, we included only those patients who were classified as having clinical inertia $(n=1,499)$.

Patient characteristics included those related to the 2007 prognostic stratification guidelines of cardiovascular risk [16]. We recommended BP be measured by physicians with the usual device, in accordance with standard clinical practice guidelines [5, 16]. At the control visit, the BP was recorded twice, with an interval of 5 minutes, with the patient rested and seated. If the difference between these two measurements was $>5 \mathrm{mmHg}$, a third measurement was taken. The average of the two or three measurements was considered to be the BP for the purposes of therapeutic decision making. Cardiovascular risk was classified into four categories: low $(<15 \%)$, moderate (15-19\%), high (20-30\%), and very high ( $>30 \%)$ [11], and analyzed by comparing a 'high' plus 'very high' risk with a 'low' plus 'moderate' cardiovascular risk.

The type of treatment was evaluated as monotherapy, fixed-dose combination therapy (two active components in one tablet), and free-dose combination therapy (two or more free-dose tablets). Healthcare setting was evaluated according to whether the ambulatory patient was seen in primary care centers or hospital hypertension units. Poor BP control was defined by clinical guidelines $[5,16]$ as $\mathrm{SBP} \geq 140 \mathrm{mmHg}$ and/or diastolic $\mathrm{BP}$ (DBP) $\geq 90 \mathrm{mmHg}$; in patients with diabetes or established cardiovascular or renal disease, the values were $\mathrm{SBP} \geq 130 \mathrm{mmHg}$ and/or DBP $\geq 80 \mathrm{mmHg}$. The reasons offered to physicians to explain why they did not intensify treatment, were as follows: (i) accepting small elevations above goal BP as adequate; (ii) being unable to exclude the possibility of white-coat hypertension; (iii) perceived difficulty in managing the BP due to the clinical condition of the patient; (iv) perceived difficulty in achieving the guideline goals; (v) not being able to rule out noncompliance with nonpharmacological measures; (vi) patient already taking "a lot of drugs" for BP control; (vii) patients would not be able to tolerate intensification of drug therapy; (viii) hypertensive patients in whom it was impossible to reduce the BP further; (ix) not being able to rule out noncompliance with drugs; (x) treatment indicated by specialists; (xi) refractory hypertension; (xii) patient didn't want to take 
any more pills; (xiii) impossible to be sure BP has been correctly measured; (xiv) interaction with other drugs; (xv) low cardiovascular risk; and (xvi) other reasons. More than one reason could be chosen.

The statistical analysis was done with SPSS Statistics 17.0 for Windows (SPSS Inc., Chicago, IL, USA) and STATA (StataCorp LP, College Station, TX, USA) programs. A univariate analysis was conducted and the chisquared $\left(\chi^{2}\right)$ test was used in bivariate analysis to compare qualitative variables and the Student $t$ test to compare the qualitative variable with another quantitative variable. The $95 \%$ confidence intervals (CIs) were calculated for the most important variables.

Binomial logistic regression multivariate analysis, adjusted for physician, was also performed, with clinical inertia considered as the dependent variable. Data were collected using a personal digital assistant computer and were sent from the physician's office to the reception center and the statistics agency for analysis of both quality control and statistics.

The study followed the EU recommendations and norms of Good Clinical Practice. Any personal data necessary for the study was treated in accordance with the Spanish Royal Decree 1720 of 21 December 2007, related to the requirements for data protection and confidentiality.

\section{Results}

Table 1 shows characteristics of included hypertensive patients. In patients with clinical inertia, the mean age was $66.0 \pm 11.9$ years, the mean SBP was $140.2 \pm 12.4 \mathrm{mmHg}$, and the mean DBP was $81.1 \pm 8.9 \mathrm{mmHg} ; 51.8 \%$ had known cardiovascular disease (i.e. secondary prevention), $42.8 \%$ had diabetes, $72.3 \%$ were taking some type of combination therapy, and $90.3 \%$ (95\% CI 88.8-91.8) had high cardiovascular risk.

Physicians gave a reason for not changing treatment despite poor BP control in 30.1\% (95\% CI 27.8-32.4) of patients $(n=451)$, and no reasons were given in $69.9 \%$ (95\% CI 67.6-72.2) of patients $(n=1,048)$. No significant differences in cardiovascular risk were found between the justified and unjustified clinical inertia groups (89.1 vs. $90.8 \% ; p>0.05)$.

Table 2 shows the reasons provided by physicians to explain clinical inertia. Main reasons were small elevations above goal BP deemed not relevant by the clinician $(27.3 \%)$; presence of co-morbidity made BP more difficult to manage $(26.8 \%)$; and suspicion of white coat hypertension $(25.7 \%)$. Average number of reasons was $1.84 \pm 0.78$ (95 \% CI 1.81-1.87). Two reasons were given by $53.9 \%$ of physicians.
Table 1 Patient characteristics

\begin{tabular}{ll}
\hline Characteristic & $\begin{array}{l}\text { Inertia }(n=1,499) \\
{[\%(95 \% \mathrm{CI})]}\end{array}$ \\
\hline Male & $53.7(51.2-56.2)$ \\
Type 2 diabetes mellitus & $42.8(40.3-45.3)$ \\
Obesity & $42.9(40.4-45.4)$ \\
Hypertension treatment with $\geq 2$ drugs & $72.3(70.0-74.6)$ \\
Primary care & $44.9(42.4-47.4)$ \\
Secondary prevention & $51.8(49.3-54.3)$ \\
Isolated systolic hypertension & $48.2(45.7-50.7)$ \\
Isolated diastolic hypertension & $8.9(7.4-10.4)$ \\
Joint increase of SBP and DBP & $42.9(40.4-45.4)$ \\
Age $(y e a r s)^{a}$ & $66.0 \pm 11.9(65.4-66.6)$ \\
SBP $(\mathrm{mmHg})^{\mathrm{a}}$ & $140.2 \pm 12.4(141.4-142.6)$ \\
DBP $(\mathrm{mmHg})^{\mathrm{a}}$ & $81.1 \pm 8.9(80.7-81.6)$ \\
\hline
\end{tabular}

${ }^{a}$ Figures presented as mean \pm SD $(95 \% \mathrm{CI})$

$C I$ confidence interval, $D B P$ diastolic blood pressure, $S B P$ systolic blood pressure, $S D$ standard deviation

Table 3 shows a comparison between instances of justified and unjustified clinical inertia. According to multivariate analysis, the variables associated with justified clinical inertia were higher BP values (both SBP and DBP; $p<0.001$ for both) and presence of diabetes $(p=0.012)$. No differences were found for sex, type of drug therapy, or treatment setting. The factors associated with unjustified clinical inertia were secondary prevention (to have cardiovascular disease; $p<0.001$ ) and an isolated increase of SBP or DBP or high borderline BP values $(p<0.001)$.

\section{Discussion}

Physicians gave no reason to explain why they did not intensify therapy in seven of every ten hypertensive patients with poorly controlled BP. An explanation for clinical inertia was only available for $30 \%$ of patients.

One of the main reasons given for failure to intensify therapy was high borderline BP values acceptable for the patient's clinical situation, i.e. meaning that small elevations above goal BP were not a cause of concern for clinicians (Table 2).

There was some obvious overlap in reasons for clinical inertia provided by physicians, e.g. 'difficult to manage due to co-morbidities' and 'difficult to achieve BP goals' and 'impossible to reduce BP any further' and 'patient with comorbidities in whom good BP control is more difficult to achieve' and 'refractory hypertension'. These reasons probably account for patient-related or disease-related conditions that make the decision to intensify treatment difficult. There is also overlap between 'white coat 
Table 2 Reasons for failure to intensify therapy despite poor blood pressure control

\begin{tabular}{|c|c|c|c|}
\hline Reasons reported by physicians & (n) & $(\%)$ & $\begin{array}{l}95 \% \\
\text { confidence } \\
\text { limits }\end{array}$ \\
\hline $\begin{array}{l}\text { High borderline values acceptable for } \\
\text { patient's clinical situation }\end{array}$ & 123 & 27.3 & $23.2-31.4$ \\
\hline $\begin{array}{l}\text { Difficult to manage due to clinical } \\
\text { situation (co-morbidities) }\end{array}$ & 121 & 26.8 & $22.7-30.9$ \\
\hline White coat effect suspected & 116 & 25.7 & $21.7-29.7$ \\
\hline Difficult to achieve guideline goals & 93 & 20.6 & $16.9-24.3$ \\
\hline $\begin{array}{l}\text { Noncompliance with prescribed diet/ } \\
\text { exercise suspected }\end{array}$ & 74 & 16.4 & $13.0-19.8$ \\
\hline Impossible to reduce BP further & 55 & 12.2 & $9.2-15.2$ \\
\hline Already taking too many BP drugs & 52 & 11.5 & $8.6-14.4$ \\
\hline $\begin{array}{l}\text { Patient easily decompensate (side } \\
\text { effects) }\end{array}$ & 46 & 10.2 & $7.4-13.0$ \\
\hline Noncompliance with drugs suspected & 44 & 9.8 & $7.1-12.5$ \\
\hline Treatment indicated by specialists & 28 & 6.2 & $4.0-8.4$ \\
\hline Refractory hypertension & 18 & 4.0 & $2.2-5.8$ \\
\hline $\begin{array}{l}\text { Patient does not wish to take more } \\
\text { pills }\end{array}$ & 16 & 3.6 & $1.9-5.3$ \\
\hline BP measurement could be incorrect & 10 & 2.2 & $0.8-3.6$ \\
\hline $\begin{array}{l}\text { Patient with co-morbidities in whom } \\
\text { good BP control is more difficult to } \\
\text { achieve }\end{array}$ & 8 & 1.8 & $0.6-3.0$ \\
\hline Interaction with other drugs & 6 & 1.3 & $0.2-2.4$ \\
\hline $\begin{array}{l}\text { Cardiovascular risk low despite } \\
\text { uncontrolled BP }\end{array}$ & 5 & 1.1 & $0.1-2.1$ \\
\hline Other reasons & 15 & 3.3 & $1.7-4.9$ \\
\hline Subtotal (reasons given ${ }^{\mathrm{a}}$ ) & 451 & 30.1 & $(27.8-32.4)$ \\
\hline No reasons given ${ }^{\mathrm{b}}$ & 1,048 & 69.9 & $(67.6-72.2)$ \\
\hline Total & 1,499 & 100.0 & \\
\hline
\end{tabular}

a Justified inertia ( $n=451$ patients)

b Unjustified inertia ( $n=1,048$ patients)

$B P$ blood pressure

hypertension' and 'BP measurement could be incorrect', i.e. implying BP measurement-related causes.

Justified clinical inertia was associated with higher BP values (both SBP and DBP) and diabetes. Older age was of borderline statistical significance (see Table 3).

As recent recommendations of BP targets in elderly patients are less aggressive [18] than previous goals [5, 16], the magnitude of this inertia is clearly reduced. Recommendations could vary from one guideline to another [5, $16,18]$ and, consequently, cause variations in the measured prevalence of clinical inertia, as it depends on guideline standards. These differences between various guidelines could also contribute to physicians' distrust of the optimal guideline-recommended BP goals.

This is, in fact, very common in clinical practice. If we adjust the prevalence according to age, we see that $75 \%$ of hypertensive women and $65 \%$ of hypertensive men are aged $>60$ years [19] and that three of every four patients with known cardiovascular disease have hypertension [20]. Studies [21, 22] indicate that clinical inertia can have an adverse impact on clinical outcomes because hypertensive patients need early BP control and any delay is associated with an increased incidence of cardiovascular events. Long-term follow-up studies are needed to measure the impact of clinical inertia on clinical outcomes in hypertensive patients.

Recent reappraisal of guidelines [18] has led to less aggressive BP targets in special populations such as the elderly and those with diabetes. However, at the time this study was undertaken, these recommendations had not been published. It would be of interest to design a new study to analyze the impact of these new targets on clinical inertia.

Despite less aggressive BP targets, we believe that it will still be hard to overcome clinical inertia. In our study, physicians did not intensify pharmacological treatment as they suspected other reasons for poor BP control, such as white coat hypertension, patient's non-adherence, or waiting for improvement of BP control with non-pharmacological interventions (e.g. diet and exercise). These reasons are sometimes difficult to discount in real clinical practice.

Other concerns expressed by physicians indicate a certain resistance to tackling clinical inertia, i.e. patients with 'high-borderline' BP could be accepted as being well controlled; that the co-morbid conditions are difficult to manage; that there is difficulty achieving the guidelinerecommended goals; that some patients are fragile and will not be able to tolerate intensification of therapy; that adherence is more difficult when taking multiple antihypertensive medications; or that it is impossible to reduce the BP any further, especially SBP.

The analysis of the reasons provided by physicians also suggests that it will be challenging to overcome this clinical inertia, as managing these patients is difficult because they are older and have multiple disorders requiring complex therapy. This clinical inertia could be associated with medical errors $[6,8]$.

The age-related arterial hardening and aortic stiffness seen in many elderly hypertensive patients makes it more difficult to control the SBP component [1-3, 23]. In this situation, physicians need to be educated that achieving BP goals is likely to require combination therapy with three or more antihypertensive drugs, given the likely multifactorial origin of the hypertension [1, 24, 25].

In the study by Ho et al., only $9.8 \%$ of physicians admitted to clinical inertia when they suspected noncompliance in their hypertensive patients [26]. Ambulatory BP monitoring is recommended in poorly controlled, high-risk hypertensive patients [27]. The usual attitude of 
Table 3 Bivariate and multivariate analyses of the patient and healthcare-level predictive factors according to whether the inertia was or was not justified

\begin{tabular}{|c|c|c|c|c|c|c|c|}
\hline Variables & $\begin{array}{l}\text { Inertia not justified } \\
(n=1,048)[\mathrm{n}(\%)]\end{array}$ & $\begin{array}{l}\text { Inertia justified } \\
(n=451)[n(\%)]\end{array}$ & $p$-Value & $\begin{array}{l}\text { Bivariate analysis } \\
{[\mathrm{OR}(95 \% \mathrm{CI})]}\end{array}$ & $p$-Value & $\begin{array}{l}\text { Multivariate } \\
\text { analysis [OR (95\% } \\
\text { CI)] }\end{array}$ & $p$-Value \\
\hline \multicolumn{8}{|l|}{ Sex } \\
\hline Men & $588(56.1)$ & $21.8(48.3)$ & 0.006 & $1.37(1.09-1.71)$ & 0.006 & $1.16(0.90-1.49)$ & 0.260 \\
\hline Women & $460(43.9)$ & $233(51.7)$ & & & & & \\
\hline $\operatorname{Age}^{\mathrm{a}}$ (years) & $65.7 \pm 11.6$ & $66.7 \pm 12.4$ & 0.138 & $0.99(0.98-1.01)$ & 0.237 & $0.99(0.98-1.00)$ & 0.089 \\
\hline $\mathrm{SBP}^{\mathrm{a}}(\mathrm{mmHg})$ & $138.8 \pm 10.5$ & $149.6 \pm 13.2$ & $<0.001$ & $0.92(0.91-0.94)$ & $<0.001$ & $0.93(0.92-0.95)$ & $<0.001$ \\
\hline $\mathrm{DBP}^{\mathrm{a}}(\mathrm{mmHg})$ & $79.6 \pm 8.1$ & $84.6 \pm 9.6$ & $<0.001$ & $0.93(0.92-0.95)$ & $<0.001$ & $0.95(0.93-0.97)$ & $<0.001$ \\
\hline Diabetes mellitus & $436(41.6)$ & $205(45.5)$ & 0.167 & $0.85(0.66-1.10)$ & 0.226 & $0.69(0.51-0.92)$ & 0.012 \\
\hline \multirow[t]{2}{*}{ Secondary prevention } & $583(55.6)$ & $193(42.8)$ & $<0.001$ & 1.68 (1.29-2.19) & $<0.001$ & $1.20(0.88-1.62)$ & 0.250 \\
\hline & & & & $2.02(1.40-2.80)^{\mathrm{b}}$ & $<0.001$ & $2.03(1.43-2.89)^{\mathrm{b}}$ & $<0.001$ \\
\hline Monotherapy & $283(27.0)$ & $133(29.5)$ & 0.002 & $1.43(1.09-1.89)^{\mathrm{c}}$ & 0.011 & $1.24(0.89-1.74)^{\mathrm{c}}$ & 0.208 \\
\hline FixDCT & $409(39.0)$ & $134(29.7)$ & & $0.91(0.66-1.26)^{\mathrm{d}}$ & 0.564 & $0.86(0.58-1.28)^{\mathrm{d}}$ & 0.455 \\
\hline FrDCT & $356(34.0)$ & $184(40.8)$ & & & & & \\
\hline \multicolumn{8}{|l|}{ Care level } \\
\hline Specialized & $603(57.5)$ & $223(49.5)$ & 0.004 & $1.39(0.98-1.95)$ & 0.062 & $1.09(0.74-1.62)$ & 0.662 \\
\hline Primary & $445(42.5)$ & $228(50.6)$ & & & & & \\
\hline Obesity & $434(41.4)$ & $209(46.3)$ & 0.077 & $0.82(0.65-1.03)$ & 0.086 & $0.91(0.69-1.21)$ & 0.522 \\
\hline Sedentary lifestyle & 499 (47.6) & $245(54.3)$ & 0.017 & $0.76(0.60-0.97)$ & 0.030 & $0.84(0.63-1.13)$ & 0.247 \\
\hline \multicolumn{8}{|l|}{ Elevated BP category } \\
\hline Isolated systolic & $546(52.1)$ & $177(39.3)$ & $<0.001$ & $2.05(1.67-2.51)^{\mathrm{b}}$ & $<0.001$ & $2.51(1.61-3.93)^{\mathrm{b}}$ & $<0.001$ \\
\hline Isolated diastolic & $115(11.0)$ & $18(4.0)$ & & & & & \\
\hline $\begin{array}{l}\text { Joint increase of both } \\
\text { (systolic and diastolic) }\end{array}$ & $387(36.9)$ & $256(56.8)$ & & & & & \\
\hline
\end{tabular}

${ }^{\mathrm{a}}$ Mean \pm standard deviation

b Significant variables when the BP values were introduced into the multivariate analysis by category

${ }^{c}$ Comparison between monotherapy and FixDCT

d Comparison between monotherapy and FrDCT

$B P$ blood pressure, $C I$ confidence interval, DBP diastolic BP, FixDCT fixed-dose combination therapy, FrDCT free-dose combination therapy, $O R$ odds ratio, $S B P$ systolic BP

$\bar{x} \pm \sigma:$ mean \pm standard deviation

physicians is to make a new appointment in the hope that patient behavior will change (i.e. improved adherence to medication, better compliance with prescribed diet or exercise) rather than to intensify medication. However, patient behavior seldom changes and, therefore, these patients attend the office more often than patients with good BP control, but there is still a delay in treatment change $[28,29]$. It must be that a white coat effect and noncompliance are difficult to rule out in real clinical practice. Furthermore, clinical inertia is common in older patients with diabetes and hypertension with poor BP control [30].

The mean BP values shown in Table 1 are close to normal. In our previous study, [15] we showed how inertia is related to small elevations above goal BP, and that may explain why the mean BP is low, despite all patients being poorly controlled (Table 1 ). Nearly $50 \%$ of patients had isolated SBP with normal DBP values.

Unjustified inertia was associated with patients having an isolated increase of SBP or DBP or high-borderline BP values, or existing cardiovascular disease. Inertia was higher in poorly controlled patients with borderline BP values. Patients with unjustified inertia had BP values slightly lower than did patients with justified inertia (Table 3). Physicians did not justify inertia in patients with BP only slightly above the normal values because they probably thought that the goal had been achieved. For higher BP values, physicians may have felt uncomfortable about not being able to provide a justification for not changing treatment.

Because the clinical consequences may be more severe, it is even more difficult to accept clinical inertia in patients 
with existing cardiovascular disease. However, this fact has been described in Spain and other countries [15] and will need specific effort to be addressed.

Phillips et al. [4] focused the problem of clinical inertia only on physicians. So, clinical inertia could be due to three reasons: overestimation of care provided; use of 'soft' reasons to avoid intensification of therapy; and lack of education, training, and practice organization aimed at achieving therapeutic goals. On the other hand, Okonofua et al. [7] established that not only physicians but characteristics of both patients and healthcare systems can influence clinical inertia.

Our results based on physicians' perceptions about the reasons for not intensifying treatment in poorly controlled hypertensive patents identify the characteristics of the patient as the most important reason (Table 2). Characteristics of the healthcare system are also related (Table 2). Some other reasons given could be described as 'soft reasons' to avoid intensification of therapy (i.e. impossible to reduce BP further) or could be related to lack of education, training, and practice organization aimed at achieving therapeutic goals (e.g. difficult to achieve guideline goals, acceptable cardiovascular risk despite uncontrolled BP).

Importantly, almost $70 \%$ of physicians marked the answer 'No reason to give'. It would be useful to know why these physicians did not provide a reason, but we need another study to answer this question. Perhaps we could achieve this by using a more qualitative than quantitative methodology (i.e. focus group). This attitude could be associated with overestimation of care provided, defined by Phillips et al. [4], but also with patient characteristics, suggested by Okonofua et al. [7].

In patients with diabetes, the dominant reasons for failure to intensify therapy were the perception by the provider that BP control was improving (34\%) or the belief that the patient was not compliant with diet or medications ( $25 \%$ ), and no reasons were given for $18 \%$ of patients [31]. Ogedegbe [32] found one of the major reasons for clinical inertia in hypertension was clinicians' use of soft reasons to avoid treatment intensification by adopting a 'wait until next visit' approach in response to patients' excuses. In another study [33], participants were providers who cared for 1,017 patients with uncontrolled hypertension receiving a single antihypertensive agent within Veterans Affairs primary care clinics. Most of the 135 providers classified as clinical inertia indicated 'continue current medications and I will discuss at the next visit' [33]. Waiting for another visit is also frequent for uncontrolled patients in Spain [34]. It is possible that physicians who did not give a reason for the clinical inertia in our study were also adopting a 'wait and see' approach.

Limitations of our study are those related to the crosssectional design, i.e. lack of follow-up. Regarding the patient selection process, physicians were asked to select their own cases of clinical inertia and this fact could introduce some bias; however, patients were included by consecutive sampling as they came to the office, and this method is commonly used in hypertension research.

The data reporting physicians' reasons to justify clinical inertia included the answer 'No reason to give', which was made by proactively selecting a mark in the survey tool, so this could not be a 'lost case' or a failed response.

In order to minimize measurement bias, we followed recommendations from previously published studies [1214], although it must be taken into account that having different devices to measure BP could itself introduce bias. Otherwise, for clinical inertia studies, the aim is focused more on the interpretation and attitude of physicians than on the validity of BP measure. Even so, physicians in our study were informed of the possibility that a reason for clinical inertia may be the inability to rule out an incorrect BP measurement. However, the prevalence of this reason was very low, and was included in 'other reasons' in our analysis.

Strengths of our study include the following: we were able to analyze several factors and reasons at the same time; and the proportion of losses was very low (1\%), probably because we used a short electronic data collection sheet that was easy for the physician to complete [15]. This also facilitated the real-time transmission of information from the office for analysis, thereby improving the quality of data collected; confounding factors were controlled using a physician-adjusted multivariate analysis.

In conclusion, physicians gave reasons for clinical inertia in only one of three aged hypertensive patients. The main reasons were borderline BP values, patient difficult to manage, white coat effect suspected, or difficult to achieve target BP goal. It is necessary to discuss guideline-recommended targets in elderly hypertensive patients with clinicians.

Acknowledgments The authors wish to thank all the physicians of the INERCAP study and the SEH-LELHA compliance group and Almirall S. A., for its unrestricted grant.

Conflicts of interest The authors state no conflict of interest.

\section{References}

1. Cushman WC, Ford CE, Cutler JA, Margolis KL, Davis BR, Grimm RH, et al. ALLHAT Collaborative Research Group. Success and predictors of blood pressure control in diverse North American settings: the antihypertensive and lipid-lowering treatment to prevent heart attack trial (ALLHAT). J Clin Hypertens (Greenwich). 2002; 4(6):393-404.

2. SHEP Cooperative Research Group. Prevention of stroke by antihypertensive drug treatment in older persons with isolated systolic hyertension: final results of the systolic hypertension in the elderly program (SHEP). JAMA. 1991;265:3255-64. 
3. Staessen JA, Fagard R, Thijs L, Celis H, Arabidze GG, Birkenhäger $\mathrm{WH}$, et al. Randomised double-blind comparison of placebo and active treatment for older patients with isolated systolic hypertension. The Systolic Hypertension in Europe (SystEur) Trial Investigators. Lancet. 1997;350(9080):757-64.

4. Phillips LS, Branch WT, Cook CB, Doyle JP, El-Kebbi IM, Gallina DL, et al. Clinical inertia. Ann Intern Med. 2001;135(9): 825-34.

5. Chobanian AV, Bakris GL, Black HR, Cushman WC, Green LA, Izzo JL Jr, et al. Joint National Committee on Prevention, Detection, Evaluation, and Treatment of High Blood Pressure. National Heart, Lung, and Blood Institute; National High Blood Pressure Education Program Coordinating Committee. Seventh report of the Joint National Committee on Prevention, Detection, Evaluation, and Treatment of High Blood Pressure. Hypertension. 2003;42(6):1206-52.

6. Phillips LS, Twombly JG. It's time to overcome clinical inertia. Ann Intern Med. 2008;148(10):783-5.

7. Okonofua EC, Simpson KN, Jesri A, Rehman SU, Durkalski VL, Egan BM. Therapeutic inertia is an impediment to achieving the Healthy People 2010 blood pressure control goals. Hypertension. 2006;47(3):345-51.

8. O'Connor PJ, Sperl-Hillen JAM, Johnson PE, Rush WA, Biltz G. Clinical inertia and outpatient medical errors. In: Henriksen K, Battles JB, Marks ES, Lewin DI, editors. Advances in patient safety: from research to implementation (vol. 2: concepts and methodology). Rockville (MD): Agency for Healthcare Research and Quality; 2005.

9. Redón J, Coca A, Lázaro P, Aguilar MD, Cabañas M, Gil N, Sánchez-Zamorano MA, Aranda P. Factors associated with therapeutic inertia in hypertension: validation of a predictive model. J Hypertens. 2010;28(8):1770-7.

10. Gil-Guillén V, Orozco-Beltrán D, Pérez RP, Alfonso JL, Redón J, Pertusa-Martínez $\mathrm{S}$, et al. Clinical inertia in diagnosis and treatment of hypertension in primary care: quantification and associated factors. Blood Press. 2010;19(1):3-10.

11. Ferrari P, Hess L, Pechere-Bertschi A, Muggli F, Burnier M. Reasons for not intensifying antihypertensive treatment (RIAT): a primary care antihypertensive intervention study. J Hypertens. 2004;22(6):1221-9.

12. Oliveria SA, Lapuerta P, McCarthy BD, L'Italien GJ, Berlowitz $\mathrm{DR}$, Asch SM. Physician-related barriers to the effective management of uncontrolled hypertension. Arch Intern Med. 2002;162(4):413-20.

13. Ferrari P; National Coordinators for the Reasons for not Intensifying Antihypertensive Treatment (RIAT) trial12. Reasons for therapeutic inertia when managing hypertension in clinical practice in non-Western countries. J Hum Hypertens. 2009; 23(3):151-9.

14. Márquez-Contreras E, Coca A, de la Figuera von Wichmann M, Divisón JA, Llisterri JL, Sobrino J, Control-Project Researchers, et al. Cardiovascular risk profile of uncontrolled hypertensive patients. The Control-Project study (in Spanish). Med Clin (Barc). 2007;128(3):86-91.

15. Gil-Guillén V, Orozco-Beltrán D, Márquez-Contreras E, DurazoArvizu R, Cooper R, Pita-Fernández S, et al. Is there a predictive profile for clinical inertia in hypertensive patients? An observational, cross-sectional, multicentre study. Drugs Aging. 2011;28(12):981-92.

16. Mancia G, De Backer G, Dominiczak A, Cifkova R, Fagard R, Germano G, Management of Arterial Hypertension of the European Society of Hypertension, European Society of Cardiology, et al. 2007 guidelines for the management of arterial hypertension: the Task Force for the Management of Arterial Hypertension of the European Society of Hypertension (ESH) and of the European Society of Cardiology (ESC) (published erratum appears in J Hypertens. 2007 Aug; 25(8):1749). J Hypertens. 2007;25(6):1105-87.
17. O’Brien E, Asmar R, Beilin L, Imai Y, Mallion JM, Mancia G, European Society of Hypertension Working Group on Blood Pressure Monitoring, et al. European Society of Hypertension recommendations for conventional, ambulatory and home blood pressure measurement. J Hypertens. 2003;21(5):821-48.

18. Mancia G, Laurent S, Agabiti-Rosei E, Ambrosioni E, Burnier M, Caulfield MJ, et al. Reappraisal of European guidelines on hypertension management: a European Society of Hypertension Task Force document. J Hypertens. 2009;27(11):2121-58.

19. Crescioni M, Gorina Y, Bilheimer L, Gillum RF. Trends in health status and health care use among older men. Natl Health Stat Report. 2010;24:1-18.

20. Wong ND, Lopez VA, L'Italien G, Chen R, Kline SE, Franklin SS. Inadequate control of hypertension in US adults with cardiovascular disease comorbidities in 2003-2004. Arch Intern Med. 2007;167(22):2431-6.

21. Julius S, Weber MA, Kjeldsen SE, McInnes GT, Zanchetti A, Brunner HR, et al. The Valsartan antihypertensive long-term use evaluation (VALUE) trial: outcomes in patients receiving monotherapy. Hypertension. 2006;48(3):385-91.

22. Nasser SA, Lai Z, O'Connor S, Liu X, Flack JM. Does earlier attainment of blood pressure goal translate into fewer cardiovascular events? Curr Hypertens Rep. 2008; 10(5):398-404.

23. Beckett NS, Peters R, Fletcher AE, Staessen JA, Liu L, Dumitrascu D, HYVET Study Group, et al. Treatment of hypertension in patients 80 years of age or older. N Engl J Med. 2008;358(18):1887-98.

24. Milani RV. Reaching for aggressive blood pressure goals: role of angiotensin receptor blockade in combination therapy. Am J Manag Care. 2005;11(7 Suppl):S220-7.

25. Jamerson K, Weber MA, Bakris GL, Dahlöf B, Pitt B, Shi V, ACCOMPLISH trial investigators, et al. Benazepril plus amlodipine or hydrochlorothiazide for hypertension in high-risk patients. N Engl J Med. 2008;359(23):2417-28.

26. Ho PM, Magid DJ, Shetterly SM, Olson KL, Peterson PN, Masoudi FA, Rumsfeld JS. Importance of therapy intensification and medication non-adherence for blood pressure control in patients with coronary disease. Arch Intern Med. 2008;168(3):271-6.

27. Gorostidi M, Sobrino J, Segura J, Sierra C, de la Sierra A, Hernández del Rey R, Spanish Society of Hypertension ABPM Registry investigators, et al. Ambulatory blood pressure monitoring in hypertensive patients with high cardiovascular risk: a cross-sectional analysis of a 20,000-patient database in Spain. J Hypertens. 2007;25(5):977-84.

28. Hyman DJ, Pavlik VN, Vallbona C. Physician role in lack of awareness and control of hypertension. J Clin Hypertens (Greenwich). 2000;2(5):324-30.

29. Berlowitz DR, Ash AS, Hickey EC, Friedman RH, Glickman M, Kader B, Moskowitz MA. Inadequate management of blood pressure in a hypertensive population. N Engl J Med. 1998;339(27):1957-63.

30. Federal Interagency Forum on Aging-Related Statistics. Older Americans 2010. Key indicators of well-being: federal interagency forum on aging-related statistics. Washington DC: US Government Printing Office; 2010.

31. el-Kebbi IM, Ziemer DC, Gallina DL, Dunbar V, Phillips LS. Diabetes in urban African-Americans. XV. Identification of barriers to provider adherence to management protocols. Diabetes Care. 1999; 22(10):1617-20.

32. Ogedegbe G. Barriers to optimal hypertension control. J Clin Hypertens (Greenwich). 2008;10(8):644-6.

33. Roumie CL, Elasy TA, Wallston KA, Pratt S, Greevy RA, Liu X, et al. Clinical inertia: a common barrier to changing provider prescribing behavior. Jt Comm J Qual Patient Saf. 2007;33(5):277-85.

34. Ortiz Tobarra MT, Orozco Beltrán D, Gil Guillén V, Terol Moltó C. Frequency of attendance and degree of control of type- 2 diabetic patients (in Spanish). Aten Primaria. 2008; 40(3):139-44. 